\title{
Soil microstructural changes induced by suffusion: x-ray computed tomography characterization
}

\author{
Cong Doan Nguyen ${ }^{1}$, Nadia Benahmed ${ }^{2,}$, Edward Andò ${ }^{2}$, Luc Sibille², and Pierre Philippe ${ }^{1}$ \\ ${ }^{1}$ IRSTEA, Research Unit RECOVER, 13182 Aix-en-Provence Cedex 5, France \\ ${ }^{2}$ University Grenoble Alpes, CNRS, Grenoble INP, 3SR, F-38000 Grenoble, France
}

\begin{abstract}
Suffusion is one mechanism of internal erosion, which occurs in gap-graded or broadly graded soils when the fine particles are detached and transported by the seepage flow through the void space formed by the granular soil skeleton. Suffusion is therefore a particle scale mechanism. During this microscale, the initial soil fabric may change due to both fines migration and coarse grains rearrangement, leading to an increase/decrease of global/local porosity and hydraulic conductivity, besides of a probable appearance of heterogeneity, which can, in turn, impact the mechanical behaviour of the eroded soil. In the literature, suffusion test results give only a macroscopic point of view and fail to quantify the effect of suffusion at the scale of the soil's induced heterogeneities. In this paper, $\mathrm{x}$-ray tomography is used to get microscopic observations of soil sample microstructure evolution during a suffusion test. The results reveal that suffusion is not a homogeneous process; the removal of fine particles takes place mainly around the soil sample circumference leading to a higher void ratio at the periphery. Besides, the inter-granular void ratio decreases significantly but almost uniformly throughout the sample owing to the progressive collapse and reorganization of the coarse grains induced by the loss in fines.
\end{abstract}

\section{Introduction}

Suffusion is defined as the migration of fine soil particles within the surrounding soil skeleton under seepage flow. Its occurrence may reduce the safety of earthen hydraulic structures such as embankment dams and dikes. Suffusion can lead to an increase in global hydraulic conductivity and seepage velocities as well as settlement in some cases [1], resulting in a change of the soil microstructure, hence affecting the mechanical behaviour of soil.

The suffusion results in literature give generally a macroscopic point of view and the evolution of soil microstructure (the scale of the soil's induced heterogeneities) usually is not explicitly mentioned in the existing analysis. In addition to the present work, only few and very recent visualisations and analyses of suffusion at grain scale can be mentioned in the literature, either by Hunter \& Bowman based on optical techniques [3], or by Mehdizadeh \& Disfani based on X-ray tomography [2].

In the present study, microscopic observations of a soil sample during a suffusion test are investigated using $\mathrm{x}$-ray tomography. The changes of the void ratio, inter-granular void ratio and fines content were followed during each suffusion step corresponding to different flow rates.

\section{Investigation of suffusion at microscopic scale}

\footnotetext{
* Corresponding author: nadia.benahmed@,irstea.fr
}

\subsection{X-ray tomography}

The full-field measurement provided by $\mathrm{x}$-ray tomography is a revolutionary and increasingly used technique in experimental geomechanics. A spatial resolution greater than one millimetre was firstly used in the study of shear bands in granular soils by Desrues et al. [4]. Thereafter, imaging at particle scale with a resolution of a few microns recently started to be implemented in soil mechanics [5,6]. In the more specific field of internal erosion, recent works by Homberg et al. [7], Fonseca et al. [8], Dumberry et al. [9], Mehdizadeh \& Disfani [2], Nguyen et al. [10], and Taylor et al. [11] have used x-ray CT with high spatial resolution.

In this study, the suffusion test in-operando x-ray tomography is used to study microstructural evolution during a suffusion test.

\subsection{Suffusion erosion permeameter test in- operando x-ray tomography}

A schematic diagram of the suffusion erosion permeameter test (SEPT) is shown in Figure 1. It consists of a cylindrical plexiglass cell. The inlet of the cell is connected to a pump while the outlet is connected to a soil particle collecting system placed inside a water tank under atmospheric pressure. The soil sample is $70 \mathrm{~mm}$ in diameter and $140 \mathrm{~mm}$ in height. The hydraulic system is 
constituted of a closed loop with controlled flow rate by a pump.

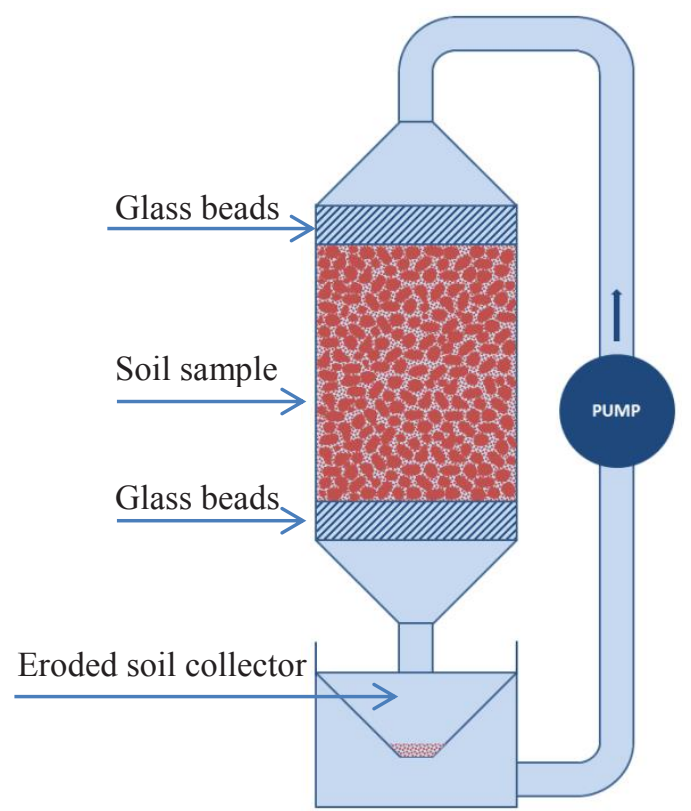

Fig. 1. Schematic diagram of the suffusion erosion permeameter test (SEPT).

The tested material is a gap-graded soil made of a binary mixture of fine particles (HN34) and coarse particles (HN 1/2.5), and whose grain size distribution is given on Figure 2. The mixture has a fines content $f=0.25$ by mass (FC25) $\left(f=M_{f} /\left(M_{f}+M_{g}\right) ; M_{f}\right.$ and $M_{g}$ are mass of fine particles and coarse grains, respectively). The initial relative density of the specimen is $40 \%$ or equivalent to the initial void ratio $e=0.529$.

The soil specimen is prepared by moist tamping method to prevent soil segregation inside the permeameter. Beforehand, a rough transparent plastic sheet is set against the inner wall of the permeameter to reduce possible preferential flows between it and the soil.

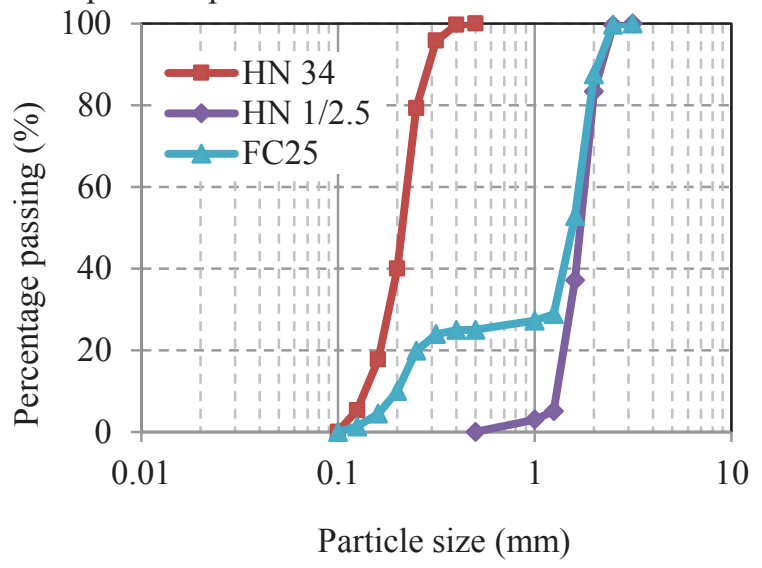

Fig. 2. Grain size distribution curves of the coarse grains (HN $1 / 2.5)$, the fine particles (HN34) and the binary mixture.
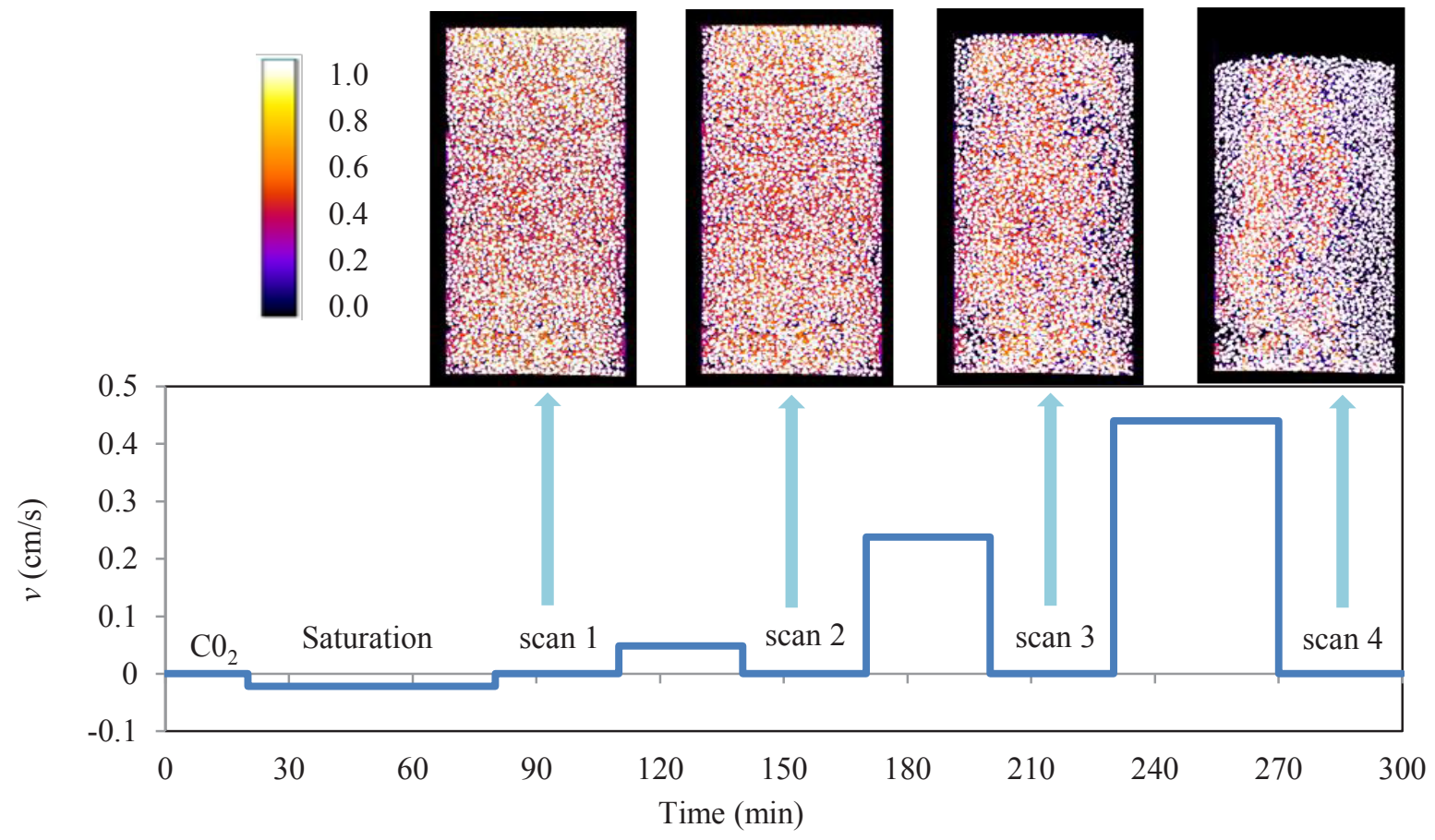

Fig. 3. Illustration of the hydraulic loading and of the 4 scans in a median section with colour-scale representation of the distribution of fine fraction concentration during the suffusion test.

After that, the suffusion test is conducted following a multi-stage procedure and is divided into two main phases: the saturation phase and the erosion phase. The saturation phase consists of circulating $\mathrm{CO}_{2}$ through the soil sample followed by circulating de-aired water at a very low flow rate in the upward direction. Next, the erosion phase is conducted in the downward direction, with an increasing flow rate process as illustrated in Figure 3. At the end of each step, the flow is stopped to perform an x-ray tomography while the eroded mass is collected and later weighted after oven drying. 4 scans were performed in this test, corresponding to 4 successive sample states during the suffusion test. 


\section{Results}

\subsection{Image processing}

A detailed description of the x-ray device and of the image processing is not presented here but can be found in Nguyen et al. [9]. After reconstruction from the x-ray tomography scans, the reconstituted images are in the form of a $3 \mathrm{D}$ volume of $900 \times 900 \times 1700$ voxels. The voxel size is $90 \mu \mathrm{m}$ that corresponds to $0.43 \mathrm{~d}_{50}$ of fine particles and $0.053 \mathrm{D}_{50}$ of coarse particles $\left(\mathrm{d}_{50}\right.$ and $\mathrm{D}_{50}$ are the median particle size of fines and coarse grains, respectively). Each voxel has a grey-level that represents the reconstructed $\mathrm{x}$-ray attenuation at the corresponding location in the sample. The 3D reconstructed scans of the soil sample include only three phases: coarse grains, fine particles and pure water, each of them having a different grey-level. The image processing based on grey-level distribution allows us to identify first the coarse fraction and then the distribution of fine particles in the intergranular spaces.

Figure 3 shows a vertical section in the median section of each scan using a colour map for the degree of filling of fine particles in the inter-granular space. Qualitatively, scan 1 shows an almost homogeneous distribution of the fines content. Comparison of scan 1 and 2 indicates that no noticeable erosion appears at very low flow rate. On the contrary, in scans 3 and 4 a significant drop in fines content is observed, especially at the edges of the sample, reflecting that the suffusion occurred, and that the removal of fine particles is located mainly at the periphery of the sample.

\subsection{Physical properties: global values, vertical profiles and radial profiles}

The evolution of the physical properties (fines content $f$, void ratio $e$, and inter-granular void ratio $e_{g}$ ) of the sample during the suffusion process is firstly presented as a whole, at the sample scale (Figure 4a, 5a, 6a). The $e_{g}$ is calculated using the following equation [12]:

$$
e_{g}=\frac{e+f}{1-f}
$$

where $e$ is the global void ratio and $f$ is the fines content.

At sample scale, no visible global change in physical properties is observed between scan 1 and 2 since no significant washout of fine particles has occurred in this step. From scan 2 to 4 , as the flow velocity is increased, the fines content globally decreases with the development of the erosion, coming together with the decrease of intergranular void ratio resulting from successive settlements of the sample. This leads to an increase in void ratio due to a slight predominance of the microstructure opening (induced by fines erosion). Nevertheless, the sample scale does not allow us so far for more thorough analysis of suffusion.

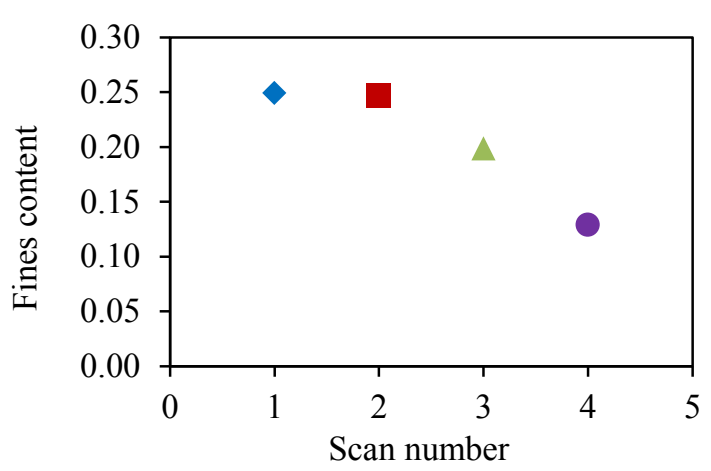

(a) Globalvalues of fines content
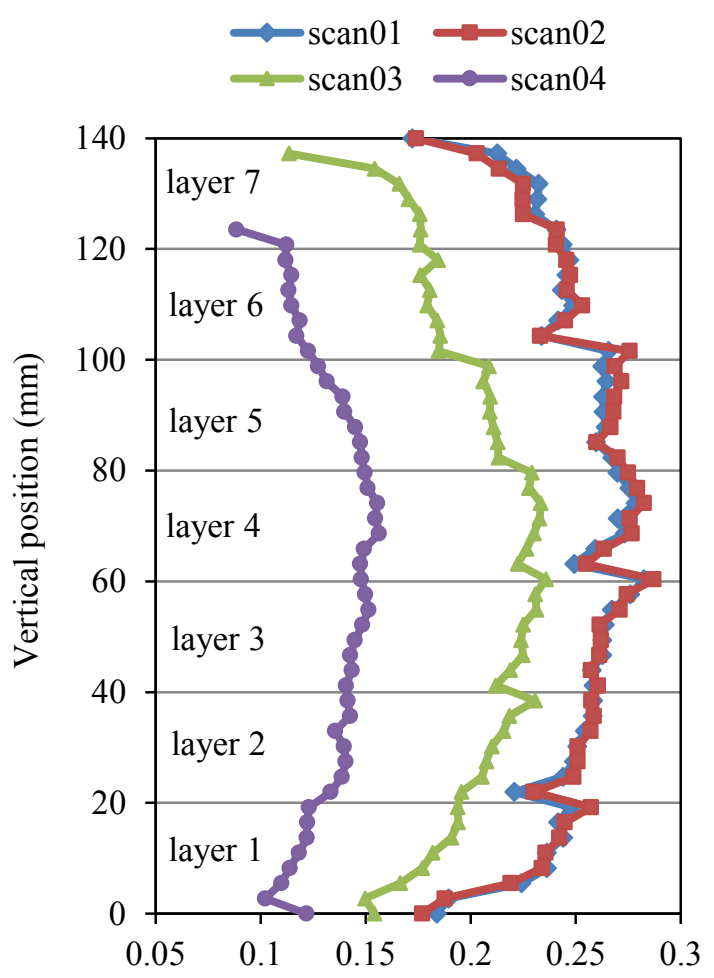

Fines content

(b) Vertical profiles of fines content

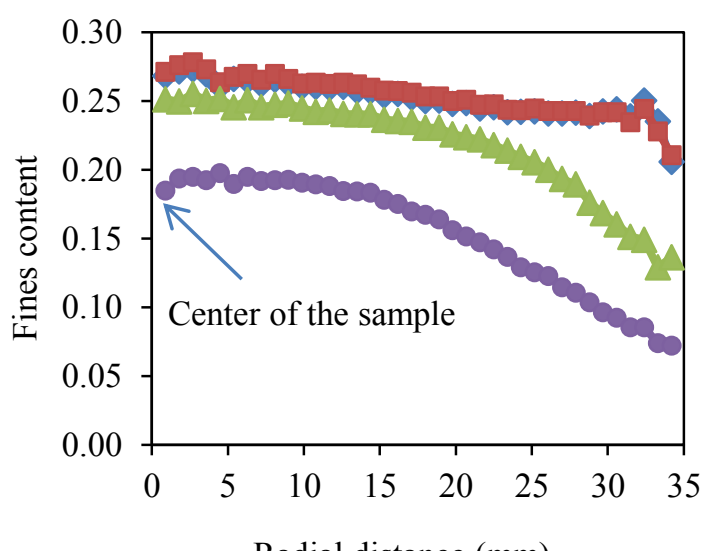

Radial distance ( $\mathrm{mm}$ )

(c) Radial profiles of fines content

Fig. 4. Global values and vertical and radial profiles of fines content for the four scans. 


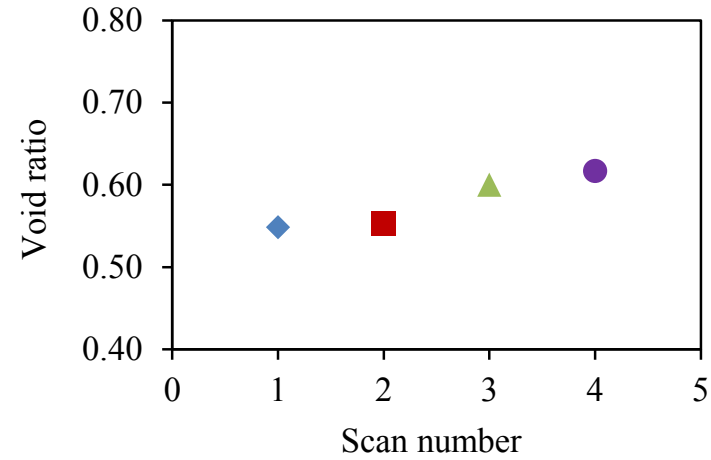

(a) Global values of void ratio

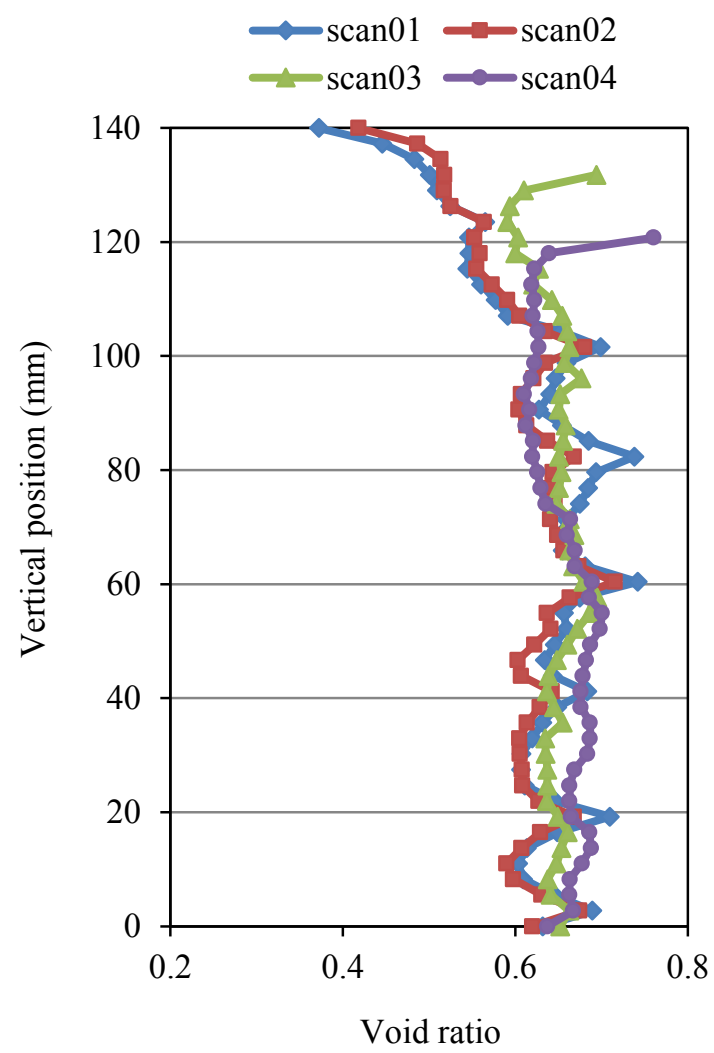

(b) Vertical profiles of void ratio

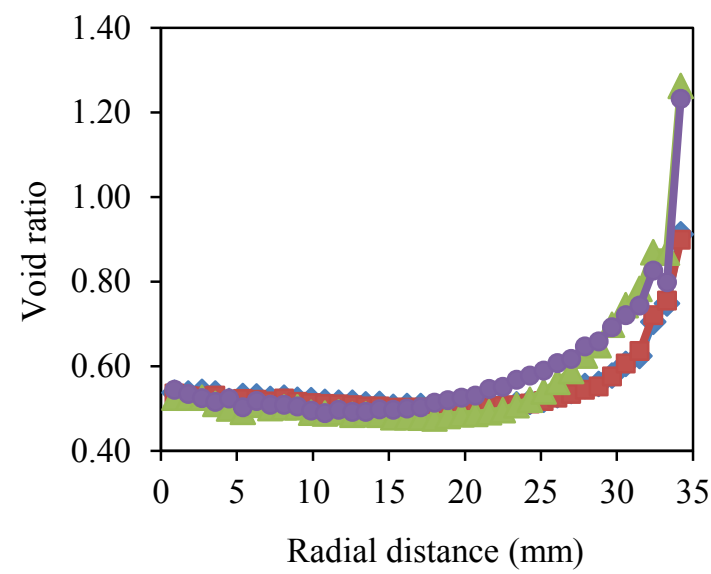

(c) Radial profiles of void ratio

Fig. 5. Global values and vertical and radial profiles of void ratio for the four scans.

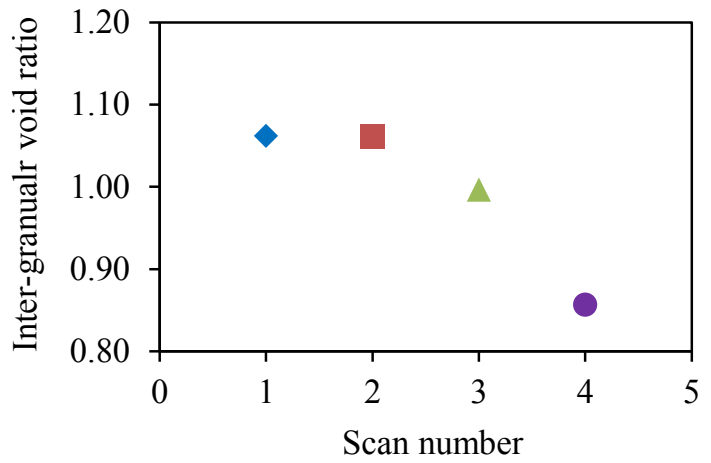

(a) Global values of inter-granular void ratio

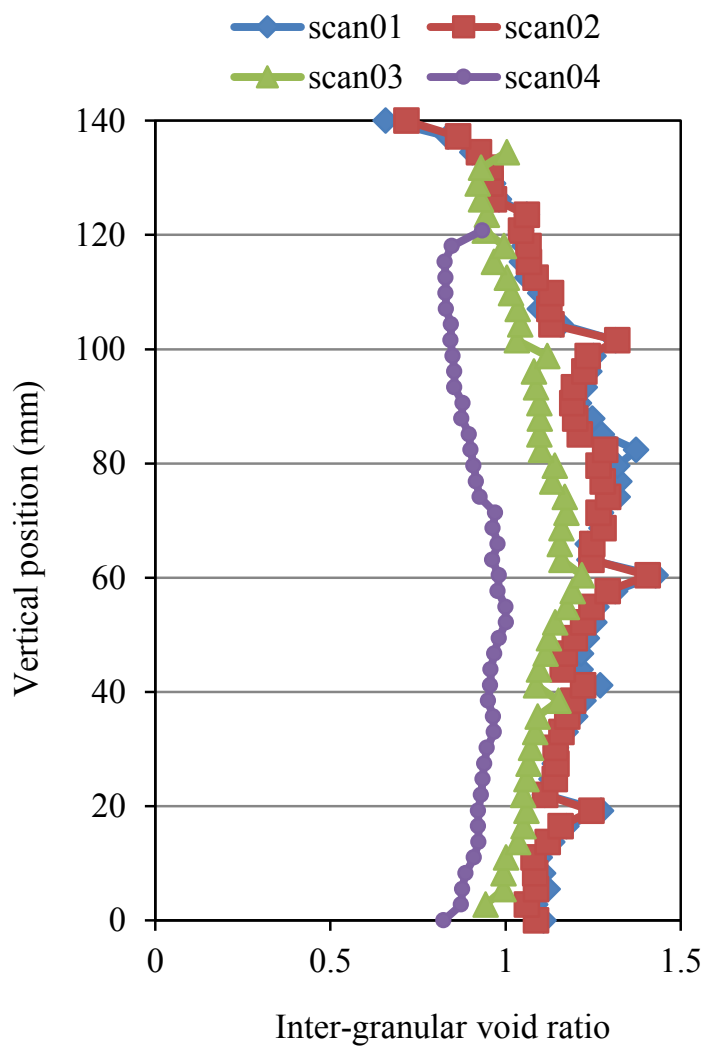

(b) Vertical profiles of inter-granular void ratio

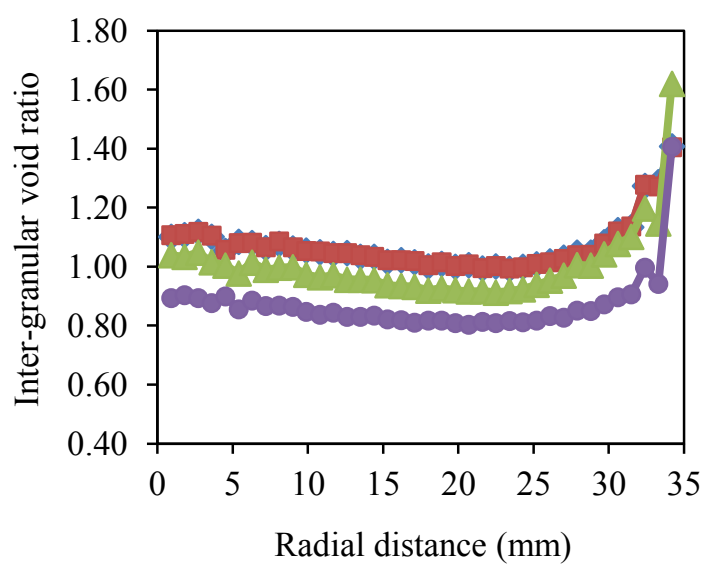

(c) Radial profiles of inter-granular void ratio

Fig. 6. Global values and vertical and radial profiles of inter-granular void ratio for the four scans. 
To go more into detail, the vertical (Figure $4 b, 5 b, 6 b$ ) and radial (Figure $4 c, 5 c, 6 c$ ) profiles of the evolution of the physical properties have been computed. Interestingly, on the vertical profiles, the interfaces between the layers deposited by the moist tamping method are clearly visible in scan 1 and 2, still distinguishable in scan 3 and ultimately disappeared in scan 4 due to both the washout of fine particles and the substantial rearrangement of coarse grains.

Still on vertical profiles, there is a substantially smaller fines content in the top and bottom layers, due probably to the reconstitution method and saturation stage. At the very small flow velocity, the global amount of fines content remains constant since the washout of fines particles is not yet observed in scan 2. Afterward, scan 3 and 4 are characterised by a significant drop of the fines content throughout the entire sample height as erosion occurs. This decrease in fines content leads to a slight increase in void ratio. Consistently, the intergranular void ratio decreases significantly due to the progressive collapse and reorganisation of the coarse grains.

As regards of radial profiles, the edge effects and related heterogeneity are clearly visible, even for scan 1 . This might be due to the preparation method combining moist tamping and saturation.

The evolution of fines content from scan 1 to 2 is almost negligible, as expected through the flow velocity was too slow for the occurrence of erosion. In scan 3 and 4 , where significant suffusion occurred, the loss in fine particles near the periphery is much higher compared to the one in the centre and there is a rather progressive decrease of fines content as the radius increases. Concerning the evolution of the void ratio, one should notice, in the centre of the sample, approximatively for $\mathrm{r} / \mathrm{R}<0.5$ ( $\mathrm{R}$ : sample radius), the void ratio is slightly lower. Regarding the inter-granular void ratio, it seems that only a global compaction of soil skeleton is observed without significant induced heterogeneity.

\section{Conclusions}

This paper presents the observations made at the microscopic scale of the erosion mechanism using $\mathrm{x}$-ray tomography, which allow a better understanding of this phenomenon.

After occurrence of suffusion, only the distribution of the inter-granular void ratio remained fairly homogeneous, while the fines content and the void ratio of the sample are characterised by strong heterogeneities, particularly at the periphery of the sample, inducing certain singularities.

The existence of such pronounced heterogeneities raises to question as to the validity interpretations (assuming the homogeneity of the medium) of mechanical tests at sample scale (as triaxial compression tests), that would be performed on eroded soil specimens.

\section{References}

1. S. Bonelli. Erosion in geomechanics applied to dams and levees: John Wiley \& Sons (2013).

2. A. Mehdizadeh \& M.M. Disfani. Micro scale study of internal erosion using 3D X-Ray tomography, 9th International Conference on Scour and Erosion (ICSE-9) (2018).

3. R.P. Hunter \& E.T. Bowman. Visualisation of seepage-induced suffusion and suffosion within internally erodible granular media. Géotechnique. 68(10): p. 918-930 (2018).

4. J. Desrues, R. Chambon, M. Mokni, and F. Mazerolle. Void ratio evolution inside shear bands in triaxial sand specimens studied by computed tomography. Géotechnique. 46(3): p. 529-546 (1996).

5. A. Hasan \& K. Alshibli. Experimental assessment of 3D particle-to-particle interaction within sheared sand using synchrotron microtomography. Géotechnique. 60(5): p. 369 (2010).

6. S. Hall, M. Bornert, J. Desrues, Y. Pannier, N. Lenoir, G. Viggiani and P. Besuelle. Discrete and continuum analysis of localised deformation in sand using X-ray [mu] CT and volumetric digital image correlation. Géotechnique. 60(5): p. 315 (2010).

7. U. Homberg, D. Baum, S. Prohaska, U. Kalbe, K. J. Witt: Automatic Extraction and Analysis of Realistic Pore Structures from $\mu \mathrm{CT}$ Data for Pore Space Characterization of Graded Soil. 6th International Conference on Scour and Erosion (ICSE-6) (2012).

8. J. Fonseca, W. Sim, T. Shire and C. O'Sullivan. Microstructural analysis of sands with varying degrees of internal stability. Géotechnique. 64(5): p. 405-411 (2014).

9. K. Dumberry, F. Duhaime, and Y.A. Ethier. Erosion monitoring during core overtopping using a laboratory model with digital image correlation and X-ray microcomputed tomography. Canadian Geotechnical Journal. 55(2): p. 234-245 (2017).

10. C.D. Nguyen, N. Benahmed, E. Andò, L. Sibille, P. Philippe. Experimental investigation of microstructural changes of soils eroded by suffusion using X-ray tomography, accepted in Acta Geotechnica (2018).

11. H.F. Taylor, C. O'Sullivan, W.W. Sim. A new method to identify void constrictions in micro-CT images of sand. Computers and Geotechnics. 69: p279-290 (2015)

12. S. Thevanayagam. Effect of fines and confining stress on undrained shear strength of silty sands. Journal of Geotechnical and Geoenvironmental Engineering, 124(6), 479-491 (1998). 